\title{
IMPACT OF PREVENTIVE THERAPY ON REGULATING MECHANISMS OF DECIDUAL MACROPHAGE POLARIZATION IN PREGNANT WOMEN WITH HIGH RISK OF PREECLAMPLSIA
}

DOI: 10.36740/WLek202109118

\author{
Volodymir K. Likhachov, Viktoriya L. Vashchenko, Olena 0. Taranovska \\ POLTAVA STATE MEDICAL UNIVERSITY, POLTAVA, UKRAINE
}

\begin{abstract}
The aim: This study was aimed at analyzing the impact of preventive therapy for pregnant women at a high risk to develop preeclampsia on the normalization of the mechanisms of decidual macrophage polarization.

Materials and methods: The methodology was designed to obtain data on the content of pro- and anti-inflammatory cytokines and indicators of nitric oxide and arginase metabolism in cervical mucus. The ration between M1 / M2 decidual macrophages in the placenta was determined by applying immunohistochemical methods. The effectiveness of the proposed therapy for the secondary prevention of preeclampsia (metformin, vitamin D3 and corvitin) was evaluated.

Results: Pregnant women with preeclampsia showed the imbalance between pro- and anti-inflammatory cytokines in favour of TNF- $a$ and INF- $\gamma$ under the decrease in IL-10 that results in an imbalance in the activity of enzymes regulating L-arginine metabolism, with increased iNOS activity and decreased arginine activity. In the placentas of the pregnant women with preeclampsia, in contrast to the healthy pregnant women, $\mathrm{M} 1$ decidual macrophages are found as predominant. The women, who received the course of the preventive therapy with metformin, vitamin D3 and corvitin, showed a decrease in the concentration of pro-inflammatory cytokines and an increase in anti-inflammatory cytokine IL-10, normalization of the balance between iNOS and arginase activity, and the normalization of the M1 / M2 macrophages ratio.

Conclusions: Normalization of the balance between pro- and anti-inflammatory cytokines, iNOS and arginase activity in cervical mucus, the ratio between decidual M1 and M2 macrophages as results of the therapy proposed reduce the incidence of preeclampsia and associated complications.
\end{abstract}

KEY WORDS: preeclampsia, cytokines, iNOS, arginase, decidual macrophages

Wiad Lek. 2021;74(9 p.l):2123-2127

\section{INTRODUCTION}

Despite the wealth of reports on the diagnosis and prevention of preeclampsia, the frequency of pregnancies and childbirths complicated with this pathology in Ukraine and throughout the world is ranging from 7 to $16 \%$; moreover, no tendency to decrease is being observed. Pregnancies complicated with preeclampsia rank the third and fourth places in the structure of maternal mortality $[1,2]$. Perinatal mortality under severe uncorrected forms of preeclampsia makes up $53-100 \%$ o $[3,4]$. To date, there have been proposed more than 30 theories of the development of preeclampsia $[5,6]$. This has led to the development of a large number of schemes for managing patients with the condition [7]. Unfortunately, the analysis of unsatisfactory results of preeclampsia therapy shows the lack of effective methods for prevention and successful management of the complex pathology $[4,8,9]$.

Decidual macrophages (DMP) are involved in the formation of the "maternal-foetal" dialogue. The number of DMP increases in the first trimester of pregnancy, then remains unchanged through the second trimester, and goes up again during the labor $[10,11]$. The activation of placental and decidual macrophages can accelerate the production of various mediators, including those that contribute to the development of endothelial dysfunction and preeclampsia $[9,14]$.

The role of macrophage polarization in the context of preeclampsia development is still insufficiently explored, therefore a detailed analysis of this issue as well as identifying factors, which can impact DMP differentiation in women with preeclampsia will be of great clinical importance for predicting the occurrence of this condition and its management.

\section{THE AIM}

This study aims at analyzing the effect of the preventive therapy we elaborated for pregnant women at high risk to develop preeclampsia on the normalization of the mechanisms of decidual macrophage polarization in the second trimester and the early third trimester of gestation.

\section{MATERIALS AND METHODS}

Methodology applied in the study enabled us to obtain data on the content of pro- and anti-inflammatory cytokines 
and indicators of nitric oxide and arginase metabolism in cervical mucus depending on the length and course of pregnancy. We investigated the balance of subpopulations of decidual macrophages $\left(M_{1}\right.$ and $\left.M_{2}\right)$ in the placenta, evaluated the effectiveness of the proposed method of the secondary prevention of preeclampsia.

The research design and the selection of participants for clinical groups met the current requirements of clinical epidemiology in terms of uniform standards of result presentation, with clear regulation of statistical methods applied. The research was carried out in accordance with the international guidelines to promote and ensure respect for all human subjects and protect their health and rights consistent with the ethical principles of Tokyo Declaration of the World Medical Association, the Declaration of Helsinki, the European Convention on Human Rights and Biomedicine, Laws of Ukraine, and regulations of the Ministry of Public Health of Ukraine.

The authorities of healthcare settings and women wished to be included into the study were fully informed about its purposes. All patients gave written informed consent to participate as subjects of the study, which was approved by the Commission on Ethical Issues and Biomedical Ethics of the Ukrainian Medical Dental Academy.

The women were divided into three clinical groups:

- control group (CG) included 30 healthy pregnant women with no risk factors for preeclampsia, steady blood circulation through the spiral uterine arteries in the placental area at 18-20 + 6 weeks of gestation, no infection was detected in the cervical canal. Material for immunohistochemical examination of placental subpopulations of macrophages $M_{1}$ and $M_{2}$ (as a control, for comparison with data in the study groups) was obtained in the second trimester during evective labor from healthy women with monochorionic monoamniotic twins without obstetric and extragenital pathology, who were operated on at 32 weeks of gestation.

- study group (SG) consisted of 91 pregnant women with a high risk of preeclampsia, impaired blood flow in the spiral uterine arteries in the placental area at 18-20+6 weeks of gestation, no infection of the lower genital tract was detected. The pregnant women were divided into two subgroups:

- SG-I included 32 pregnant women who refused the secondary preventive therapy of preeclampsia we elaborated, and received the treatment according to existing guidelines (75 mg of acetylsalicylic acid and $2 \mathrm{~g}$ of calcium in terms of active agents);

- SG-II involved 59 pregnant women who received the secondary preventive therapy of preeclampsia we developed (metformin, vitamin D3, and corvitin).

The groups of women by age, social status, features of menstrual function, parity, obstetric history and structure of extragenital diseases were homogeneous that allowed us to obtain more reliable results by comparing the findings in the course of our study.

We investigated the concentrations of pro- and anti-inflammatory cytokines (TNF- $\alpha$, INF- $\gamma$, IL-10) and the activity of iNOS and arginase in cervical mucus of the pregnant women with preeclampsia and the corresponding indicators in the healthy pregnant women, then compared these indicators with the number of $M_{1}$ and $M_{2}$ decidual macrophages in the placentas of the examined women.

Cytokine concentration was assessed by immune-enzyme assay using the standard commercial reagent kits ("Vector BEST") in accordance with the manufacturer's instructions.

NO-synthase activity was assessed by the difference in nitrite concentration before and after the cervical mucus incubation. Nitrates concentration was measured by determining the diazo compounds yielded from the reaction with sulfanilic acid, followed by the reaction with a-naphthylamine (Griess-Ilosvay's reagent). The activity of the inducible form of NO-synthase was defined as the difference between the total activity of NO-synthase and the activity of its constitutive forms [15].

The determination of total arginase activity in cervical mucus was based on calculating the difference in L-ornithine concentration before and after the incubation in phosphate buffer solution containing L-arginine. The L-ornithine concentration was determined by the color of the product yielded from the reaction with Chinard reagent in modification of V. A. Khramov [15].

Immunohistochemical study of $M_{1}$ and $M_{2}$ macrophages was performed in placental tissue taken from spontaneous preterm births (or cesarean delivery) in the second and the early phase of the third trimester of gestation by indirect biotin-extravidin-peroxidase method on 5- $6 \mu \mathrm{m}$ paraffin-embedded sections. The method is based on the interaction between tissue antigen and specific antibodies. Immunohistochemical study was carried out in the pathomorphological laboratory "CSD Health Care" (Kyiv), which is a member of the European quality control system NordiQC.

The findings were processed by a PC "Asus F3Ke" using the statistical program "STATISTICA" ("StatSoft Inc., USA).

\section{RESULTS}

Studying the dynamic changes in pro-inflammatory and anti-inflammatory cytokine profiles in physiological pregnancy and pregnancy complicated by preeclampsia, we have found out that pregnant women at a high risk of preeclampsia (SG-I) showed a significant increase in the content of pro-inflammatory cytokines INF- $\gamma$ and TNF- $\alpha$. The INF- $\gamma$ concentration in cervical mucus of SG-I was $13.06 \pm 0.70 \mathrm{pg} / \mathrm{ml}$ compared to $10.42 \pm 0.51 \mathrm{pg} / \mathrm{ml}$ in the CG $(\mathrm{P}<0.01)$, and TNF- $\alpha$ content in the SG-I equalled to $7.05 \pm 0.54 \mathrm{pg} / \mathrm{ml}$ compared to $3.40 \pm 0.24 \mathrm{pg} / \mathrm{ml}$ $(\mathrm{P}<0,001)$ in the CG.

The pregnant women under the study demonstrated the increase in the content of pro-inflammatory cytokines, while the content of anti-inflammatory cytokine IL-10 significantly reduced, reaching $6.14 \pm 0.19 \mathrm{pg} / \mathrm{ml}$ in the SG-I (versus $9.56 \pm 0.63 \mathrm{pg} / \mathrm{ml}$ in the control group; $\mathrm{P}<0.001$ ). 
According to the opposing changes in the content of pro- and anti-inflammatory cytokines, the TNF- $\alpha$ / IL-10 coefficient progressively went up from $0.36 \pm 0.02$ in CG to $1.15 \pm 0.06$ in SG-I $(\mathrm{P}<0.001)$.

We investigated the activity of iNOS and arginase in cervical mucus in the healthy pregnant women (control group) and in the pregnant women at high risk of preeclampsia who refused to take the secondary prevention therapy we elaborated. It has been revealed that the activity of iNOS in SG-I significantly increases $(2.90 \pm 0.27$ $\mu \mathrm{mol} / \mathrm{min} / 1 \mathrm{~g}$ of protein in SG-I against $1.24 \pm 0.16$ $\mu \mathrm{mol} / \mathrm{min} / 1 \mathrm{~g}$ of protein in the control group; $\mathrm{P}<0.001$ ). A strong positive correlation was found between iNOS activity and the content of pro-inflammatory cytokine TNF- $\alpha$ in cervical mucus $(r=0.78 ; \mathrm{P}<0.001)$, and a moderately strong correlation was detected between iNOS activity and the content of pro-inflammatory cytokine INF- $\gamma(r=0.56 ; \mathrm{P}<0.01)$.

In contrast to the iNOS activation, the activity of arginase in cervical mucus in the pregnant women of SG-I compared with the control significantly diminished in 1.7 times $(1.3 \pm 0.15 \mu \mathrm{mol} / \mathrm{min} / 1 \mathrm{~g}$ of protein in OG-I against $2.21 \pm 0.19 \mu \mathrm{mol} / \mathrm{min} / 1 \mathrm{~g}$ of protein in CG; $\mathrm{P}<0,001$ ). There was a negative correlation between an increase in iNOS activity and a decrease in arginase activity in cervical mucus in the patients of SG-I $(\mathrm{r}=-0.41 ; \mathrm{P}<0.05)$, and a positive correlation between a decrease in the content of anti-inflammatory cytokine IL-10 and a decrease in arginase activity in cervical mucus $\left(\mathrm{r}=0.54 ; \mathrm{P}_{1}<0.02\right)$.

Based on these data obtained, we can conclude that in pregnant women with preeclampsia there appears an imbalance between pro- and anti-inflammatory cytokines in favour of TNF- $\alpha$ and INF- $\gamma$, when IL-10 decreases that in turns results in an imbalance in the activity of enzymes regulating L-arginine metabolism, and the iNOS activity increases. The activity of arginine significantly reduced.

Given the fact that INF- $\gamma$ and iNOS are involved in the differentiation of decidual macrophages and stimulate the $M_{1}$ subpopulation, while IL-10 and arginine contribute to the production of the $M_{2}$ subpopulation [16], and inappropriate macrophage polarization is associated with abnormal pregnancies [12], this raised an urgent need to investigate the real ratio between these subpopulations of decidual macrophages in the placentas of women who had preeclampsia.

The findings of immunohistochemical study demonstrated that in the placentas of women with preeclampsia the content of $\mathrm{M}_{1}$ decidual macrophages was 1.7 times higher than their number in healthy women, while the content of $\mathrm{M}_{2}$ macrophages, on the contrary, decreased in 1.5 times. Accordingly, the $M_{1} / M_{2}$ ratio in patients with preeclampsia significantly went up in 2.5 times $(1.06 \pm 0.30$ in the patients with preeclampsia versus $0.42 \pm 0.043$ in healthy women; $\mathrm{P}<0.05)$.

Significant correlations were found out between the content of $M_{1}$ macrophages in the placenta of the women, who had preeclampsia in the second trimester or in the early phase of the third trimester, and the content of pro-inflammatory cytokine INF- $\gamma(\mathrm{r}=0.65 ; \mathrm{P}<0.05)$ and inducible NO synthase $(\mathrm{r}=0.59 ; \mathrm{P}<0.05)$. We also detected significant correlations between a fall in the content of $\mathrm{M}_{2}$ macrophages in the placenta of the above mentioned women and a decrease in the content of the anti-inflammatory cytokine IL- $10(r=0.49 ; \mathrm{P}<0.05)$ and a decline in arginase activity in cervical mucus $(\mathrm{r}=0.60 ; \mathrm{P}<0.02)$.

That is, in contrast to the healthy pregnant women, $M_{1}$ decidual macrophages (due to the INF- $\gamma$ stimulating effect and inducible NO synthase activation) in the placenta are predominant in the women with preeclampsia that probably results in the placental dysfunction in the second trimester and early third trimester. Such disturbances in decidual macrophage differentiation in these time intervals of gestation towards the $M_{1}$ decidual macrophages are probably one of the pathophysiological mechanisms of preeclampsia development.

Taking into account the findings obtained, the secondary preventive therapy of preeclampsia should be aimed at restoring the correct differentiation of subpopulations of decidual macrophages (suppression of $\mathrm{M}_{1}$ phenotype production and stimulation of $\mathrm{M}_{2}$ phenotype), as well as at enhancing blood flow in arterial uterine arteries to prevent the intrauterive foetal hypoxia.

In order to solve these issues we applied the integrated therapy elaborated for the following purposes: to inhibit the differentiation of decidual macrophages into $\mathrm{M}_{1}$ subpopulation (metformin) [17,18], to stimulate the differentiation of $M_{2}$ macrophages (vitamin $D_{3}$ ) [19], and to improve uterus blood circulation (corvitin) [8].

Metformin depending on the dosage inhibits the release of pro-inflammatory cytokines IL- $1 \beta$, IL- 6 and TNF $\alpha$ in human macrophages and endothelial cells; it also inhibits the secretion of TNFa due to a decrease in the activity of NF-kB (nuclear transcription factor) with a subsequent decrease in the differentiation of decidual macrophages into the $M_{1}$ subpopulation $[17,18]$. Metformin was prescribed to be taken at a dose of $500 \mathrm{mg}$ a day for a long period, starting since the blood circulation reducing in the placental spiral arteries, approximately $18-20+6$ weeks prior the due date of labour

Vitamin D3 acts as a regulator of decidual immunity, and the placenta is one of the main links for the extrarenal synthesis of $1.25[\mathrm{OH}] 2 \mathrm{D}$. It has been shown that 1.25 $[\mathrm{OH}] 2 \mathrm{D}$ not only promotes the differentiation of M2 macrophages, but also inhibits the differentiation of M1 macrophages [19]. We prescribed 2000 IU a day, starting since the detection of decreased blood circulation in the uterine spiral arteries in the placental area 18-20+6 weeks prior the due date of labour.

Corvitin is a complex of quercetin $(500 \mathrm{mg})$ and povidone (molecular weight $7100-11000 \mathrm{kD}, 450 \mathrm{mg}$ ). Quercetin depending on the dosage increases the nitric oxide concentration in endothelial cells that promotes the restoration of regional blood circulation and microcirculation without significant changes in vascular tone. The medicine also inhibits the production of pro-inflammatory cytokines IL-1b, IL- 8 that reduces the imbalance between 
vasodilators and vasoconstrictors. Corvitin was administered intravenously in a dose of $500 \mathrm{mg}$ dissolved in 100 $\mathrm{ml}$ of saline once a day for 10 days. This therapy pattern was repeated twice a pregnant.

In contrast to the growth in pro-inflammatory cytokine concentration in the pregnant women of the SG-I, the participants of the SG-II who received the course of preventive therapy demonstrated a decrease in the concentration of these cytokines with their approximation to the values of the healthy women of the control group: INF- $\gamma$ in cervical mucus in SG-II was $11.30 \pm 0.70 \mathrm{pg} / \mathrm{ml}$ against $10.42 \pm$ $0.51 \mathrm{pg} / \mathrm{ml}$ in CG $(\mathrm{P}>0.2)$, and the TNF- $\alpha$ content in OG-II was $4.04 \pm 0.82 \mathrm{pg} / \mathrm{ml}$ compared to the value of $3,40 \pm 0,24 \mathrm{pg} / \mathrm{ml}$ in the control group $(\mathrm{P}>0,1)$. Moreover, the concentration of anti-inflammatory cytokine IL-10 in SG-II significantly grew, reaching the value of $8.93 \pm 0.54$ $\mathrm{pg} / \mathrm{ml}$ compared to the value of $9.56 \pm 0.63$ in healthy pregnant women $(\mathrm{P}>0.2)$. The coefficient of TNF- $\alpha$ / IL10 in SG-II decreased significantly compared with that in SG-I $(0.45 \pm 0.10$ vs. $1.15 \pm 0.06 ; \mathrm{P}<0.001)$.

The women of SG-II demonstrated the normalized of the balance between iNOS and arginase activity. These values approached those of the control group: iNOS was $1.24 \pm 0.16 \mu \mathrm{mol} / \mathrm{min} / 1 \mathrm{~g}$ of protein in CG and $1.51 \pm$ $0.20 \mu \mathrm{mol} / \mathrm{min} / 1 \mathrm{~g}$ of protein in SG-II, P>0, 2, arginase was $2.21 \pm 0.19 \mu \mathrm{mol} / \mathrm{min} / 1 \mathrm{~g}$ protein and $2.09 \pm 0.21$ $\mu \mathrm{mol} / \mathrm{min} / 1 \mathrm{~g}$ protein, respectively; $\mathrm{P}>0.5$.

Having analyzed the findings obtained on completion of the preventive therapy, we found out the placentas of women in SG-II, who took the therapy, the content of $\mathrm{M}_{1}$ decidual macrophages lowered in 1.35 times compared with the women of OG-I (69.4 \pm 5.0 / 10 fields of vision in SG-II compared with $94.2 \pm 5.2$ / 10 fields of vision in SG-I; $\mathrm{P}<0.002$ ), approaching the values in the healthy pregnant women ( $56.5 \pm 4.5$ / 10 fields of vision; $\mathrm{P}>0.05$ ). The content of $\mathrm{M}_{2}$ macrophages, on the contrary, increased in 1.4 times (123.7 $\pm 7.1 / 10$ fields of vision in SG-II compared with $88.6 \pm 6.7$ / 10 fields of vision in SG-I; $P<0.002$ ), and approached the values in the healthy pregnant women (135.0 $\pm 6.4 / 10$ fields of vision; $P>0.2$ ). Accordingly, the ratio of $\mathrm{M}_{1} / \mathrm{M}_{2}$ in the pregnant women SG-II significantly decreased to $0.56 \pm 0.06$, approaching that of the control group: $0.42 \pm 0.043, \mathrm{P}>0.05$ with a value of $1.06 \pm 0.2$ $(\mathrm{P}<0.05)$ in SG-I.

\section{DISCUSSION}

Summarizing the results of the study, it can be argued that in pregnant women with the manifestation of preeclampsia the following dysregulatory features of immunity were revealed:

- significantly increased levels of pro-inflammatory cytokines INF- $\gamma$ and TNF- $\alpha$ with a significant decrease in the concentration of anti-inflammatory cytokine IL-10; such changes contribute to the inability of trophoblast cells to provide an adequate invasion in the spiral arteries of the uterus with the subsequent development of endothelial dysfunction in such women $[8,9]$;
- imbalance of pro- and anti-inflammatory cytokines leads to an imbalance of enzymes that regulate L-arginine metabolism, with an increase in iNOS activity and a significant decrease in arginase activity $[13,15]$;

- decidual macrophages of the M1 subpopulation dominate in the placenta (due to the stimulating effect of INF- $\gamma$ and activation of inducible NO synthase), which causes placental dysfunction in the second and early third trimester of pregnancy (because activated M1 macrophages cause cytotoxic effects on placental tissue). [11,16];

- there is a non-physiological decrease in the subpopulation of M2 in the placenta during pregnancy, which causes more frequent complications of pregnancy and childbirth $[1,9,16])$.

The application of our proposed method for secondary prevention of preeclampsia in pregnant women at high risk for this disease (metformin, vitamin $\mathrm{D}_{3}$, corvitin) has led to significant positive changes in the immune system with a corresponding improvement in clinical consequences:

- there was a decrease in the concentration of pro-inflammatory cytokines (INF- $\gamma$ and TNF- $\alpha$ ) and an increase in the concentration of anti-inflammatory cytokine IL- 10 in cervical mucus in the main group II with a corresponding decrease in the ratio of TNF- $\alpha$ / IL-10; and these indicators approached those in the control group;

- normalization of the balance of iNOS and arginase activity was observed in women of the main group II, taking our recommended medications; these indicators approached those in the control group;

- the content of decidual macrophages of the M1 phenotype decreased by 1.4 times as compared to women in the main group I, approaching that in healthy pregnant women; the content of macrophages of the M2 phenotype, on the contrary, increased by 1.4 times, also approaching the level of healthy pregnant women.

Thus, we can suggest that the therapy we applied prevented circulatory disorders in the uterine-placental system, reduced the incidence of preeclampsia in 1.4 times and the incidence of severe preeclampsia in 2.6 times, significantly diminished the incidence of pregnancy complications associated with preeclampsia including a 2.2 -fold decrease in the frequency of premature births. Perinatal mortality lessened from $62.5 \%$ in SG-I to 33.9 \%o SO-II; neonatal asphyxia lowered to 4 -fold less incidence; the cases of extremely low birth weight went down in 2.1 times.

\section{CONCLUSIONS}

1. Pregnant women with preeclampsia demonstrate imbalance between pro- and anti-inflammatory cytokines in favour of TNF- $\alpha$ and INF- $\gamma$ under the decrease in IL10 that results in an imbalance in the activity of enzymes regulating L-arginine metabolism, with increased iNOS activity and decreased arginine activity.

2. In the placentas of the pregnant women with preeclampsia in contrast to the healthy pregnant women, $M_{1}$ decidual macrophages are found as predominant, while the content of $\mathrm{M}_{2}$ macrophages, on the contrary, 
decreases in 1.5 times. Such dominance of decidual macrophages of the $M_{1}$ subpopulation (due to the INF- $\gamma$ stimulating effect and of inducible NO synthase activation) can likely cause placental dysfunction during the pregnancy.

3. The women of SG-II, who received the course of the preventive therapy with metformin, vitamin D3 and corvitin, showed a decline in the concentration of pro-inflammatory cytokines and an increase in anti-inflammatory cytokine IL-10, normalization of the balance between iNOS and arginase activity, and the normalization of the $M_{1} / M_{2}$ macrophages ratio.

4. It has been clinically proved that the preventive therapy with metformin, vitamin D3 and corvitin prevents circulatory disorders in the uterine-placental system, reduces the incidence of preeclampsia and pregnancy complications associated with preeclampsia, and lessens perinatal mortality and the incidence of neonatal asphyxia.

Prospects for further research: to investigate the morphological mechanisms of the adverse effect of $M_{1}$ decidual macrophages on the placental function in the second and the early third trimester of pregnancy in women with preeclampsia.

\section{REFERENCES}

1. Zaporozhan V.M., Chayka V.K., Markin L.B. et al. Akusherstvo: pidruchnyk; tom 1. [Obstetrics: textbook; volume 1]. Za red. V.M. Zaporozhana. K.: Medytsyna. 2017, 1032p. (in Ukrainian).

2. Trends in maternal mortality: 1990 to 2015 : estimates by WHO, UNICEF, UNFPA, World Bank Group and the United Nations Population Division. Geneva: World Health Organization. 2015.

3. Abalos E., Cuesta C., Carroli G. et al. Pre-eclampsia, eclampsia and adverse maternal and perinatal outcomes: a secondary analysis of the World Health Organization Multicountry Survey on Maternal and Newborn Health. BJOG. 2014; 121(1):14-24.

4. Medved'V.I., ZhukS.I., Kon'kov D.H. et al. Tyazhka preeklampsiya. CALM DOWN - alhorytm diy medychnoho personalu. [Severe preeclampsia. CALM DOWN - algorithm of actions of medical staff] Zdorov'e zhenshchyny. 2017;10 (126):28-33. (in Ukrainian).

5. Radzinskiy V.E., redaktor. Akusherstvo: uchebnik. [Obstetrics: textbook.] M.: GEOTAR-Media; 2016, 1040p. (in Russian).

6. Likhachov V.K., Dobrovol's'ka L.M., Semenyuk L.M., Yaremchuk L.V. Akusherstvo i hinekolohiya: Praktykum. [Obstetrics and gynecology: Workshop.] Poltava: Dyvosvit. 2014, 200p. (in Ukrainian).

7. Akusherstvo: Natsional'noye rukovodstvo. [Obstetrics: National guidelines.] M.: GEOTAR-Media. 2015,1200 p. (in Russian).

8. Humenna I.Y.E. Perspektyvy klinichnoyi diahnostyky i likuvannya endotelial'noyi dysfunktsiyi u vahitnykh z arterial'noyu hipertenziyeyu. [Prospects for clinical diagnosis and treatment of endothelial dysfunction in pregnant women with hypertension.] Aktual'ni pytannya pediatriyi, akusherstva ta hinekolohiyi. 2018;1: 66-71. (in Ukrainian).

9. Kon'kov D.H., Bulavenko 0.V., Dudnyk V.M., Buran V.V. Suchasni aspekty patohenetychno obumovlenoyi profilaktyky preeklampsiyi. [Modern aspects of pathogenetically determined prevention of preeclampsia.] Perynatolohyya y pedyatryya. 2016;1: 46-50. (in Ukrainian).

10. Erlebacher A. Immunology of the maternal-fetal interface. Annu. Rev. Immunol. 2013;31: 387-411.
11. Faas M.M., Spaans F., de Vos P. Monocytes and macrophages in pregnancy and pre- eclampsia. Front. Immunol. 2014;30 (5): 298.

12. Murashko A.V. Angiogennyye faktory rosta v patogeneze preeklampsii. Arkhiv akusherstva i ginekologii im. V.F. Snegireva. [Angiogenic growth factors in the pathogenesis of preeclampsia] 2015; 2(3): 4-7. (in Russian).

13. Murashko L.E., Fayzullin L.Z., Murashko A.V. Rol' endotelina v patogeneze preeklampsii [The role of endothelin in the pathogenesis of preeclampsia]. Akusherstvo i ginekologiya. 2013; 11:4-8. (in Russian).

14. Savel'yeva G.M., redaktor. Akusherstvo: natsional'noye rukovodstvo. [Obstetrics: a national guide.] M.: GEOTAR-Media. 2015, 1088p. (in Russian).

15. Kostenko V.0. Metodyka vyznachennya zahal'noyi arhinaznoyi aktyvnosti, vmistu nitrytiv ta aktyvnosti N0-syntazy. [Method for determination of total arginase activity, nitrite content and N0-synthase activity]. Navchal'nyy posibnyk. Poltava: Drukarnya Ukrayins'koyi medychnoyi stomatolohichnoyi akademiyi. 2017, 16p. (in Ukrainian).

16. Van den Bossche J., Baardman J., de Winther M. Metabolic characterization of polarized $\mathrm{M} 1$ and $\mathrm{M} 2$ bone marrow-derived macrophages using real-time extracellular flux analysis department of medical biochemistry, experimental vascular biology. Academic medical center,Amsterdam, 2015:, 24p.

17. Kalafat E., Sukur Y.E., Abdi A. et al. Metformin for prevention of hypertensive disorders of pregnancy in women with gestational diabetes or obesity: systematic review and meta-analysis of randomized trials - Ultrasound Obstet Gynecol 2018;52:706-714.

18. Romero R., Erez 0., Huttemann M. et al. Metformin,the aspirin of the 21st century: its role in gestational diabetes mellitus, prevention of preeclampsia and cancer, and the promotion of longevity. Am J Obstet Gynecol. 2017; 217: 282-302.

19. Wasnik S., Rundle C.H., Baylink D.J. et al. 25-Dihydroxyvitamin D suppresses M1 macrophages and promotes M2 differentiation at bone injury sites. JCl Insight. 2018;3(17):11.

\section{ORCID and contributionship:}

Volodymyr K. Likhachov: 0000-0003-4823-022X $X^{\text {, E, F }}$

Viktoriya L. Vashchenko: 0000-0002-6897-6339

Olena O. Taranovska: 0000-0003-3409-7130 ${ }^{\circ}$

\section{Conflict of interest:}

The Authors declare no conflict of interest.

\section{CORRESPONDING AUTHOR Volodymyr K. Likhachov}

Poltava state medical university

42 Stritenska Str., app. 19, Poltava 36011, Ukraine

tel: +380952212112

e-mail:vladimir.lihachev@gmail.com

Received: 05.11 .2020
Accepted: 02.08.2021

A - Work concept and design, B - Data collection and analysis, C - Responsibility for statistical analysis, D-Writing the article, $\mathbf{E}$-Critical review, $\mathbf{F}$ - Final approval of the article 